\title{
EVALUATING KNOWLEDGE AND PRACTICE OF HAND WASHING MESSAGES AMONG SECONDARY SCHOOL STUDENTS IN ANAMBRA STATE
}

\author{
By \\ Nonye Benedeth Ezeaka, PhD \\ Department of Mass Communication \\ ChukwuemekaOdumegwuOjukwu University \\ Igbariam Campus \\ nonyeben@yahoo.com \\ Chinwe Beatrice Ezeoke, $\mathrm{PhD}$ \\ Department of Mass Communication \\ NnamdiAzikiweUniversity \\ Awka \\ emesco23001@yahoo.com \\ Mrs Ebele Glory Nwodu \\ Department of Mass Communication \\ ChukwuemekaOdumegwuOjukwu University \\ Igbariam Campus
}

\begin{abstract}
The study examined the Knowledge and Practice of handwashing messages among Secondary School Students in Anambra State, Nigeria. The essence is to enhance the spread of infections like diarrhoea, Ebola and other diseases associated with dirty hands and contacts. It is premised against the background that students live, and interact closely and there is the need to control the spread of bacteria among these students through proper handwashing. The objectives include; to determine whether the respondents' know about handwashing messages; the respondents' source of handwashing messages and to determine whether the respondents practice handwashing after exposure to handwashing messages. The study was anchored on the Diffusion of Innovation Theory and Theory of Reasoned Action. It also adopted a survey research method with the questionnaire as the instrument for data collection. The study used multi-stage sampling techniques to select three schools from the three senatorial districts in Anambra State. The total population for the study was 121,087 junior secondary school students from where a sample of 384 respondents was studied. Descriptive statistical tools - mean, frequencies and percentages were used in answering research questions. Results showed that there was no significant relationship between the knowledge of handwashing messages and the practice of handwashing. Results further showed that respondents had experience of handwashing messages. Sequel to the findings, the researcher recommended, among others, the need to mobilize handwashing with soap and water at critical times to ensure greater compliance.
\end{abstract}

Keywords: Handwashing, Knowledge, Practice, Handwashing messages, Secondary school

\section{INTRODUCTION}

Handwashing is not only important for personal hygiene; but also a religious and cultural practice for many people. The tradition of handwashing started many years ago. The link surrounding handwashing and health was initially observed less than two centuries ago in 1846 by Ignaz Philipp Semmelweis, a physician from Hungary, regarded as the progenitor of hand sanitation. He observed that greater number of the pregnant women from his hospital 
that gave birth in the medical student/doctor run maternity ward mostly developed fever that resulted to deaths compared to the mid-wife-run maternity for pregnant women in the adjacent ward. During the investigation, it was discovered that doctors and medical students were not exposed to appropriate hand sanitation after autopsies before visiting the maternity ward. This however justifies the early attestation that proper hand sanitation could prevent infection.

However, in an attempt to promote and mobilize people everywhere to upgrade their hygiene habits especially on the aspect of washing hands with soap, the campaign on handwashing was instituted in 2008 by the Global Handwashing Partnership GHP; in Stockholm, Sweden during the Annual World Water Week. Other members of GHP; were United Nations Children Fund (UNICEF), Unilever, USAID, World Bank, Procter and Gamble and other international agencies. The United Nations UN; General Assembly selected October 15 of every year as the handwashing day. GHP; (2017) noted that every year, more than 200 million persons are part of the celebrations in more than 100 countries of the world. In Nigeria, handwashing awareness was officially launched on May 22, 2008 at Federal level by the then former First Lady of the Federal Republic of Nigeria HajiaTuraiYar'Adua with the Acting United Nations Children Fund (UNICEF) delegate in Nigeria Dr Robert Limlim and other dignitaries. Hand washing campaign was brought in as a peculiar method for hygiene advancement in alliance with the Federal Government/UNICEF Water, Sanitation and Hygiene (WASH) events in 2004. The general missions of the campaigns include:

(i) To elevate the degree of awareness of hygiene; and sanitation particularly hand washing for the stakeholders, children and the entire society;

(ii) To mobilize the policymakers, opinion leaders, community leaders and the entire society on the importance of handwashing as it pertains to health and the economic well-being of the populace;

(iii) To campaign for greater monetary and bureaucratic responsibilities for hygiene promotion; and

(iv) To advance for sustainable development; of WASH for accomplishing the MDGs;

Checkmating of infectious diseases is part of the problems facing developing countries. In line with the advantages of hygiene advancement particularly hand washing for the promotion of man's welfare and growth, UNICEF in association with Nigerian Government and some Non-Governmental Organization; are advancing the furtherance of handwashing sensitizations; at the State, Local Government with schools and at community levels. Nigeria participated in the first international hand washing ceremony on October 15, 2008 in consonance with the global goal of propagating a culture of washing hands with soap and water. Handwashing awareness was inaugurated to emphasize and accelerate the process of sanitation growth. It is the uncomplicated and the easiest method of avoiding most known infectious diseases that cause mortality in the environment. Hand hygiene involves handwashing, the utilization; of disinfectant for washing hands. Katie (2015) notes that throughout the previous few decades, health communications have become a widely recognized; and validated discipline, a critical component to most health programmes.

World Health Organization (WHO) (2005) reiterates that health is not just the shortage of disease but a "state of thorough bodily, psychological and general well-being." The need to better the well-being of people across the world relies upon acceptable recognition of the societal convention and economic condition of the content through which the general health issues are actualized. Umueri\&Galadima (2008) noted that health status of people in any 
geographical setting is so imperative that if the leaders of that nation fold their arms and do nothing to better their well-being, it will merely be a moment before plagues or diseases will ravage such people. Following the commitment to advance the health of the people, different handwashing messages are organized; to inform, persuade, educate and dissuade the diversified, critical and seasoned audience. In this vein, the media and multi-media approaches have been significant later in the campaign against societal health diseases. DeBuck, Remoortel, Veegaete\& Young (2017) explained that Sustainable Development Goal for sanitation is to achieve access to adequate and equitable sanitation and hygiene; for all and end open defecation, paying special attention to the needs of women and girls and those in vulnerable situations by 2030 .

Effective communication; can as well promote the knowledge, awareness and the best practical way of creating understanding on an issue. Communication is, therefore, essential in championing healthcare delivery. Different rallies and carnivals; Behavioural Change Communication materials; jingles on broadcast media; discussion programmes relating to health; documentary; drama; features on print media and so on have been utilized; to pass the message across. Olukanni (2013) revealed that the provision of safe water, sanitation and hygiene; in schools had been established to improve health and boost educational achievement.

\section{STATEMENT OF THE PROBLEM}

The Nigerian society was threatened in the past with occurrence of Ebola virus and monkeypox diseases. According to Ilesanmi\&Alele (2016) factors like lack of knowledge, limited or lack of infection prevention and control resources, insufficient public health amenities and extremely endemic structure of virus provoke and accelerate the outbreak of diseases. One of the ways of contracting diseases is the hand, arousing the exigency for appropriate hand hygiene. UNICEF (2007) explains that large numbers, consisting of urban/ rural schools and health centres, still lack access to adequate sanitary facilities like latrines and handwashing facilities. Infrequent hand washing is a poor hygienic exercise that can trigger diseases like diarrhoea, cholera and others. The means of spreading these viruses is through blood contact and bodily fluids of infected persons, Olalekan et al. (2014).

Also, Olukanni (2013) notes that most public secondary schools in Nigeria are short of the necessary water/sanitation facilities and hygiene education programmes are often inadequate. Hands are contaminated through many ways like after defecation, sneezing into the hands, contacts with pets and animals; babies used diapers and so on. Illness is a hindrance to the progress of both child and adult, which could affect the socio-economic life of the nation. Apart from family, schools are the most important places of learning for students for they have a central place in society. When Water, Sanitation and Health (WASH) amenities are lacking, or are poorly used and managed, schools grow into unsafe environment for disease transmission UNICEF (1998).

To address all these mentioned health concerns, government and other international agencies have endorsed the application of communication interposition or approach to achieve positive changes and improve the value of life through handwashing messages. In all these, it is not clear if the respondents in the study areas are favourably disposed to these interventions. This circumstance obviously motivated this study that investigates the knowledge and practice of handwashing messages among the respondents in the study area. To the researcher, it is a 
major gap in knowledge that calls for empirical examination. This, in essence is the major problem the study resolves to investigate.

\section{RESEARCH QUESTIONS}

1. Do the respondents have knowledge of handwashing messages?

2. What are the respondents' sources of information about handwashing messages?

3. Do the respondents' support handwashing practice after exposure to handwashing messages?

\section{THEORITICAL FRAMEWORK}

Theories entail a clear explanation regarding why a particular concept behaves in a specific way (Nwodu 2017). This study is anchored on two theories, the Diffusion of Innovation Theory and the Theory of Reasoned Action. The Diffusion of Innovation Theory was developed by Everett Rogers in 1945, popularized; in 1962. Rogers (2003) defines diffusion as the process by which an innovation is communicated through specific channels over time among members of a social system. The theory believes that the media and interpersonal contacts have a way of providing information which could influence opinion and judgment.

The four stages of innovation, according to Rogers, include invention, diffusion or communication; through the social system, time and consequences. Information flows through a process or network like the opinion leaders whose roles may determine the extent that the innovation will be adopted. The rate of diffusion and the degree of saturation are degrees of adoption of change in a particular community. Rishante (2011) notes that diffusion as first elaborated by Everett Rogers in 1945 outlines certain factors which have been consistently found useful by researchers in trying to understand the diffusion process as it relates to development efforts.

These factors are:

(i) the characteristics of the innovation and the degree of novelty associated with it;

(ii) the rate of diffusion is influenced by individual differences among potential adopters;

(iii) the features of the social system; and

(iv) the existing diffusion channels or networks in the particular community.

The diffusion of new ideas and ideologies for advocacy and mass mobilization; are usually targeted at non-specific, anonymous and heterogeneous audiences as in the mass media, (Rishante 2011). The theory acknowledges the mandatory role of opinion leaders, the influence of the mass media and interpersonal reinforcement of mass media messages in the individual's adoption of the decision making process. Eze (2010) explains that the more complex the health behaviour being advocated, the longer it takes to be accepted; and the more inconsistent a practice is to current practices, beliefs and norms; the longer it takes for the people to accept..

Diffusion of innovation theory provides a useful framework for studying the adoption process. Diffusion studies have found that the way targeted adopters perceive the attributes of an innovation is critical and that these perceptions account for $49-87 \%$ of the variance in whether or not they adopt (Rogers, 1995). Abdullahi, Gbaje\& Mohammed (2015) noted that Perceived attributes of innovation include: 
(i) Relative advantage - the degree to which an innovation is perceived as better than the idea it supersedes. The higher the perceived position, the more likely the change will be adopted.

(ii) Compatibility - the degree to which an innovation is perceived as consistent with the existing values, past experiences and needs of potential adopters. If the innovation is perceived as an extreme change, then it will not be compatible with past experiences and is less likely to be adopted.

(iii)Complexity - the degree to which an innovation is perceived as relatively difficult to understand and use. Changes that are perceived as complex are less likely to be adopted.

(iv) Observability - the degree to which the results of an innovation are visible to others. If the observed effects are perceived to be small or non-existent, then the likelihood of adoption is reduced.

(v) Trialability - the degree to which an innovation may be experimented with on a limited basis. This may include trying out parts of a plan or having the opportunity to watch others using a new program. Trialability is positively related to the likelihood of adoption.

The relevance of the theory to the study refers to how handwashing messages seek to communicate information that will promote handwashing, especially at critical times among secondary school students in the study areas. The change may be immediate or long term behaviour change. Nwosu (2008) asserts that intensive, well-organised, and implemented advocacy campaigns are needed for the expected results to be achieved. The flow of advocacy impacts can range from information or awareness creation, knowledge change, opinion change, attitudinal change, to behaviour, actions or practice adoption or amendment.

This study is also anchored on the Theory of Reasoned Action. This theory seeks answers to the fundamental question of why people or audience behave the way they do. The Theory of Reasoned Action TRA; was first developed by Martin Fishbein in the late 1960s but was revised and updated by Fishbein and IcekAzjen in the decades that followed. The theory analyzes; a person's intention to act or behave in a particular way in specific situations. It also suggests that a person's behaviour is determined by his/her intention to perform, and such purpose is a function of his/her attitude towards the action. Similarly, the theory also focuses on a person's attitudes towards that behaviour and even the subjective norms of influential people and groups that could influence those attitudes. The method further elaborates how attitudes towards a particular action are influenced by a combination of two related factors: our beliefs and our evaluation of the potential outcome. They provide insight into why things happen in specific ways through certain structures with certain results (Nwabueze 2012).

The theory assumes that individuals will mostly act upon their intentions which comprise of two primary attributes: an individual's attitude towards behaviour and an individual's beliefs regarding social pressures to either perform or not. Attitude is a function of beliefs- that is beliefs that the behaviour will lead to certain expected outcomes as judged by the individual, (Des Wilson \&Aniebo 2010).

The relevance of the theory to the study aptly refers to how respondents perceive handwashing messages; it could be as a result of their belief or exposures and consequently the evaluation of the potential outcome of their dispositions.

Also, the more we comprehend the attitudes and norms that influence the intent, the more accurately interventions can be designed to affect the desired direction. 


\section{EMPRICAL REVIEW}

Azuogu, Ilo, Nwimo, Azubogu \& Owunaka (2016) did a study on "the extent of handwashing practice among Secondary School Students in Ebonyi State, Nigeria”. The study noted the high incidence of infectious diseases like diarrheal among secondary schools in Nigeria; the, study explained how contaminated hands promote the transmission of infections, especially with people living in close like school. The study indicated that washing the hands with running water and soap prevents the spread of diseases. The study used a cross-sectional survey to determine the extent the secondary school students in the study area (Ebonyi State) practice handwashing exercise with a sample of 420 students from both junior and senior classes from government schools in the rural and urban area of the state; the study used a 3 point scaled while the instrument of data collection was 18 items self-structured questionnaire.

Also a Cronbach Alpha that obtained the reliability of 0.862 while T-test statistic was used for the hypotheses with 0.05 alpha level. The study found the extent of handwashing to be low among secondary school students in Ebonyi. The study revealed that findings of the study have implications towards handwashing campaign in the country and recommended the use of mass media to promote the campaign and improvement of hygiene education and its curriculum, that all the concerned agencies from the government take appropriate policies that will enhance good hygiene; in terms of education in schools, mainly the primary as well as the secondary schools in the area of creating a conducive environment for handwashing practice to improve through the provision of handwashing facilities in all the schools.

Vivas, Gelaye, Aboset, Kumie, Berhane\& William (2015) conducted a study on the "Knowledge, Attitudes and Practices KAP; of Hygiene among school children in Angola, Ethiopia," The study noted that poor hygiene practices and insufficient sanitary conditions play significant parts in the increased problem of infectious diseases, the study examined the knowledge, attitude and practice of hygiene; among rural school children in Ethiopia with a sample size of 669 students carried out in a government-owned institution from the study population made up of all Angolan primary school children from grades 1-6. The research design used was survey while the questionnaire provided both demographic questions and frequencies to which pupils maintained the personal hygiene; and issues relating to handwashing during the day, especially at critical moments. Knowledge about sanitation, proper hygiene; and presence of parasite were highlighted. The findings show that 52 per cent of the pupils knew about basic hygiene; the frequency of handwashing with soap was at 36.2 percent.

Arthi, Abarna, Bagyalakshmi, Anitharaj\&Vijayasree (2016) performed a study on "Assessment of Knowledge, Attitude and Practice of Hand Hygiene among Nursing and Medical students in a tertiary care hospital in Puducherry, India." The study used a selfadministered structured questionnaire to solicit answers from nursing and medical students. The results were analysed; with Chi-square test using SPSS 16 software to analyse; the variables of hand hygiene. A total of 140 participants were used in the study, and it was found that a good number of students had moderate knowledge of hand hygiene in contrast; the overall attitude of the participants was not satisfactory, only a few respondents show proper hand hygiene practices.

Similarly, Sultana, Mahmud, Sarker\& Hossain (2016) studied "Hand hygiene knowledge and practice among university students: Evidence from private universities of Bangladeshi". The study revealed how adequate hand hygiene could hinder the spread of infectious diseases 
The study used a cross-section of 200 students from four selected universities with pretested, semi-structured questionnaire that had a checklist relating to handwashing practice. The study found a good number of students washed their hands with water. At the same time only 22.5 percent did that effectively by following the correct procedures and frequency of handwashing using water, soap or hand sanitizer; The study used Regression coefficient to show that age is considered as a negative influence on handwashing practice while the older respondents accounted for lower scores when compared. The study also revealed insufficient hand hygiene practice by university students.

Steiner-Asiedu, Van-Ess, Papoe, Setorglo, Asiedu\& Anderson (2011) carried out a study on "handwashing practices among school children in Ghana". The study was carried out to ascertain the practice of handwashing on children in both private and public schools in Ghana with a population of 295 school children that were randomly used for the study. The study used both qualitative and quantitative methods for data collection. Copies of the questionnaire were used to gather information on demographics during checklist for observation of handwashing as well as an interview guide for focus group discussion. The study adopted a quantitative and qualitative method collection, while Focus Group Discussions were also used for data collection. Findings revealed that the majority of school children under investigation did not demonstrate good handwashing practice with soap in school and at home as a result of non-provision and open running water, soap and towel. Hand washing was poorly done in both public and private schools.

Furthermore, Ikogho \& Igbudu (2013) studied "Availability and Utilization; of handwashing facilities among primary school pupils in Ughelli North L.G.A; of Delta State" the study explained that infectious diseases if not checkmated through proper handwashing exercise could cause tremendous morbidity and mortality on school children and absenteeism at school. The study used a sample size of 50 head teachers through simple random sampling from a total population of 90 head teachers from the study area. Also, copies of the questionnaire were used for data collection and analyzed; through frequencies and arithmetic mean. Findings from the study show that the schools have few handwashing facilities and the utilization; hindered by poor maintenance culture and lack of handwashing supplies.

Merenu, Barbara \&Hornik (2015) wrote on "knowledge, attitude and practice of handwashing amongst residents of Orlu metropolis" The study was carried out during the Ebola crises in Nigeria to teach how effective preventive practices of constant and efficient handwashing are. The study aimed to determine the respondents' knowledge, attitude and practice of handwashing amongst residents of Orlu Metropolis in Imo State. The study adopted a descriptive crosssectional study and examined 405 participants; the instrument for data collection was a questionnaire that was both self-administered and interviewer-administered bearing in mind the respondents' level of literacy. It found that 97.6 percent of the respondents had a good knowledge of diseases that are contracted through dirty hands; also a good number of the respondents ( 90.4 per cent) knew of alternatives to handwashing like hand sanitizers; The study found that 93.64 percent believed that hands should be kept clean always, 92.65 percent of the respondents used soap and water for handwashing while 33.89 per cent of the respondents practised handwashing under running water. The study mentioned that the obstacle to washing hands energetically included forgetfulness 34.48 percent, 14.66 percent for lack of water, 13.48 percent due to busy schedule and ignorance at 10.40 percent. The study concluded that though the respondents washed their hands, it was neither done under running water nor dried with disposable paper towels. The washing of hands was done in basins of water. 
Asekun-Olarinmoye, Omobuwa, Adebimpe \&Aseku-Olarinmoye (2014) examined the "knowledge, attitude towards and practise of handwashing among mothers of under-five children in Igona Area of Olorunda Local Government in Oshogbo, Osun State Nigeria" The study reported how the use of dirty and contaminated hands especially while cooking and eating stimulates the transmission of germs into the body thereby causing ill-health. The study enumerated the dual roles of mothers as children's nurse who handles their faeces, as well as the family chef who takes care of family food.

The study revealed that the poor knowledge and practice of simple hygiene; increase the risk of disease dissemination. The study selected 300 mothers of under-five children through multistage sampling technique. The instrument for data collection was a questionnaire. The findings revealed that majority of the respondents had a definite knowledge of handwashing, though influenced by the level of their education and religion. Also, age and exposure to school influenced the practice of handwashing as a majority of the older respondents with higher educational exposures practised handwashing than the younger ones.

Ekanem \& Johnson (2015) evaluated "Handwashing practices at critical times among mothers in selected health facilities in AkwaIbom State" The study objectives were to examine the practices of handwashing using soap and water at critical moments and to ascertain how caregivers of under-five children practice handwashing from selected health facilities in Uyo. The study examined 219 mothers/ caregivers of under-five children from two selected primary health facilities from two Local Government Areas of Uyo Senatorial District who were present for immunization;A Self-administered questionnaire was used to solicit information for the study. The study found that 61.2 percent of the respondents washed their hands before preparing food, a total of 47 percent of the respondents washed their hands before feeding children. In comparison 84.9 percent of the respondents washed their hands after defecation.

Alula (2016) examined "Knowledge, Attitude and Practice KAP; on handwashing and associated factors among public primary school children in Hosanna town, SNNPR, Ethiopia" The study aim was to investigate the KAP study of the above topic in the study area using a sample size of 246 of the respondents from April 15-30. It used a pre-tested structured questionnaire from trained assistants. The study found that 69.9 percent of the respondents had good knowledge of handwashing which was affected by their area of residence and grades in school while 59.4 per cent also had right attitude to handwashing exercise. In terms of practice, 71.97 per cent of the respondents practised hand washing.

Setyautami, Sermsri\&Chompikul (2012) wrote on "Proper Handwashing Practices among Elementary School students in Selat sub-district, Indonesia". The study stressed that even though handwashing is regarded as the most useful and easiest way of preventing diseases, many people are yet to wash their hands correctly. The study used a cross-sectional descriptive study to explain handwashing with emphasis on the correct way of washing hands and other related issues for the sixth grade of elementary students of Sela sub-district in Indonesia. The study used 274 students from seven schools selected randomly from five villages and then used a self- administered questionnaire. Descriptive statistics were used for analyzing; data, also chi-square test and multiple logistic regressions to critically explore the various study factors. The study revealed that 40.5 percent of the respondents practised handwashing correctly. The study concluded that the practice of washing hands correctly was low among the respondents and recommended the provision of better facilities and promotion of handwashing campaign. 
Thanh \& Ngoc (2013) conducted a study on "Handwashing among school children in an ethnically diverse population in Northern rural Vietnam". The study examined the handwashing behaviour with emphasis on Hand Washing with Soap (HWWS) and found other related issues among the school children residing in multi-ethnic rural communities of northern Vietnam. The study evaluated six primary and secondary schools as well as ethnic villages comprising of four homes. The study used both quantitative and qualitative methods and logistic regression method to determine the relationships between behaviour and demographic factors. Findings show that 66 percent of the respondents (school children) practised handwashing with soap (HWWS). However, during demonstrations, it was discovered that ten school children out of 319 respondents performed handwashing with soap correctly. The study concluded that handwashing with soap in the study area was weak in terms of compliance.

White, Kolbe, Carlson \& Lipson (2005) carried out a study on "The Impact of a Health Campaign on Hand hygiene and Upper Respiratory illness among College students living in residence halls". The study aim was to determine if a campaign message on hand hygiene and the possibility of using gel hand sanitizer; would likely lower the spread of cold and flu. The study used an experimental-control in residence halls of 4 campus residence. The findings revealed that good exposure to a media campaign by the students as well as the exposure to gel hand sanitizer; added to their knowledge on health benefits.

Anthony, Salule, Tracy, George, Tara, Steven \& Kingsley (2014) conducted a study on "Knowledge, Awareness and Practice of the importance of handwashing amongst children attending state-run primary schools in rural Malawi," highlighted the objectives of the study to include: to determine Escherichia coli presence on the hands of primary school pupils numbering 126; to find out the pupils and teachers knowledge, awareness as well as hygiene practices and to determine the school environment through monitoring or observation. The study found that the greater percentage of e-coli on hands as well as the hygiene; which was not significant as the standard of the facilities for sanitation was abysmal. The study found poor evidence of understanding the necessary disease transmission from both the teachers and pupils and recommended a multidisciplinary approach that will promote sanitation.

Junxiong, Shao, Lumen \&Liyang (2015) evaluated a study on "Current Knowledge, Attitude and Behaviour of hand and food hygiene in a developed residential community of Singapore: A cross-sectional survey," The study was carried out in the residential area in the West of Singapore under a cross-sectional study from June to August 2013. A random sampling technique was used to select a total of 1,156 household units in interviewer assisted survey with a standardized; questionnaire. Survey method was used, and results analyzed; using descriptive statistics. The study conducted the test with Fisher's Exact test and multivariate logistic regression modelling. The test was done at a 5 percent level of significance and a 95 percent confidence interval where applicable. Findings show that despite a good knowledge and attitude of the respondents, the result was not able to translate to the compliance of good hygiene practices, and so it affected the motivation to perform as well.

\section{METHODOLOGY}

The study adopted survey research method. It enables the researcher to ascertain the opinions of a study group or population by examining a sample from the population, which will be generalized; 


\section{AREA OF STUDY}

The study was carried out in Public Secondary School in Anambra State, Nigeria. The study was specifically carried out from secondary schools from the three senatorial districts in Anambra State. The choice of junior secondary school students was based on the principle that handwashing awareness recognizes the use of children as behavioural change agents in society.

\section{POPULATION OF STUDY}

The population of the study was one hundred and twenty-one thousand, and eighty-seven junior secondary school students from the three senatorial districts of Anambra State.

\section{Table 1}

\begin{tabular}{ll}
\hline Population: & \\
\hline State & Anambra \\
Male & 56,888 \\
Female & 64,199 \\
Total: & 121,087 \\
\hline
\end{tabular}

2014 Student Enrolment for Public Junior Secondary School: UBEC Database 2015

\section{Sample size}

In determining the sample size, the Krejcie and Morgan table was used to determine the sample size. The population of the study which was 121,087 was known. Krejcie and Morgan (1970) table for sample size determination was applied to obtain the sample size of 384. The researchers made a total of 384 copies of the questionnaire and shared them according to the population strength of each school under study and used multistage sampling techniques because it allows the study the opportunity to vary the sampling techniques at each stage.

\section{Questionnaire Distribution and Retrieval}

\section{Table 2}

\begin{tabular}{|c|c|c|c|c|c|}
\hline $\mathbf{S} / \mathbf{N}$ & District & School & No.Distributed & No. Returned & Percentage \\
\hline \multirow[t]{3}{*}{1} & Anambra North & $\begin{array}{l}\text { Urban Girls Secondary } \\
\text { School Fegge } \\
\text { Onitsha }\end{array}$ & 128 & 120 & 93 \\
\hline & South & $\begin{array}{l}\text { Achina Girls Sec } \\
\text { School Achina }\end{array}$ & 128 & 113 & 88 \\
\hline & Central & $\begin{array}{l}\text { Community Sec } \\
\text { School Umuokpu } \\
\text { Awka }\end{array}$ & 128 & 102 & 80 \\
\hline Total & & & 384 & 335 & 87 \\
\hline
\end{tabular}

A total of 384 copies of the questionnaire were administered to the respondents, while 335 copies were retrieved and found usable. This represented $87 \%$ of the respondents. The analysis for the study was based on the 335 (87\%) respondents who were considered significant enough to make an objective analysis. 
Volume 1 Number 1 Maiden Issue

\section{DEMOGRAPHIC DATA ANALYSIS}

Table 3: Distribution of respondents by gender

\begin{tabular}{lcc}
\hline Sex & Frequency & Percentage \\
\hline Male & 107 & 32 \\
Female & 228 & 68 \\
Total & $\mathbf{3 3 5}$ & $\mathbf{1 0 0}$ \\
\hline
\end{tabular}

As shown from the table, both males and females were found in the secondary schools. Majority of the respondents were females representing 68\% while the males represented $32 \%$ of the total population under study.

Age was another demographic data considered to be relevant to the study. The age brackets of the respondents were assessed from the nine secondary schools and presented in Table 4.3

\section{Table 4: Respondents' Age Distribution}

\begin{tabular}{lcl}
\hline Age Range & Frequency & Percentage \\
\hline $10-12$ & 14 & 4 \\
$13-14$ & 282 & 84 \\
15 and above & 39 & 12 \\
\hline Total & $\mathbf{3 3 5}$ & $\mathbf{1 0 0}$
\end{tabular}

As indicated in the table, the dominant age range was between $13-14$, representing $84 \%$ of the respondents, the age range of 15 and above represented $39 \%$ while between 10-12 age range represented $14 \%$.

\section{Answers to Research Questions}

Research Question One: Awareness/ Knowledge Response

The objective one of the study was to determine whether the respondents know about handwashing messages in the study area. Thus the research question that elicited responses for the survey is: "Do the respondents know about handwashing messages?" The opinions of the respondents from the secondary schools under investigation were sought.

Table 5: Mean Distribution of Questionnaire on Knowledge/Awareness Response

\begin{tabular}{llllllllll}
\hline S/N & $\begin{array}{l}\text { Do you know about handwashing } \\
\text { messages? }\end{array}$ & SA & A & UD & D & SD & Total & Mean \\
\hline 1 & $\begin{array}{l}\text { I know little about handwashing } \\
\text { messages }\end{array}$ & 78 & 60 & 62 & 58 & 77 & 335 & 3.0 \\
& $(390)$ & $(240)$ & $(186)$ & $(116)$ & $(77)$ & $(1009)$ & \\
2. I only hear of the messages & 122 & 74 & 59 & 50 & 30 & 335 & 4.0 \\
& $\begin{array}{l}\text { I occasionally } \\
\text { 3. It is a message that encouragesthe }\end{array}$ & 145 & 60 & 47 & 39 & 44 & 335 & 4.0
\end{tabular}


proper washing of hands with soap and water.

4. It is a message for disease prevention.

(725)

(240)

(141)

(78)

(44)

(1228)

37

(148)

152

64

38

335

(990)

3.0

5. I do not know anything about the message

$\begin{array}{llllll}40 & 42 & 144 & & & 335 \\ (200) & (168) & & (100) & (59) & (959)\end{array}$

Figures in Parenthesis are Alternative Response Scale Values

The table above shows the mean distribution table of the responses to the five items in the questionnaire on knowledge/awareness of handwashing messages among the respondents.

The mean score associated with item one on research question one which has to do with knowledge response produces a mean score of 3 showing that respondents knew of handwashing messages. The second item from the questionnaire shows a mean score of 4.0, indicating that respondents got to hear about handwashing messages occasionally. The respondents agreed that handwashing message encourages the proper washing of hands with soap and water with a mean score of 4.0. Thus the mean score of 3.0 indicated that respondents believed that hand washing messages have to do with sensitization; for disease prevention. Finally, the last item on knowledge/awareness response shows the mean score of 2.86 belowthe decision rule of 3.00, indicating that respondents did not know anything about the handwashing messages. From the analysis above, the results from knowledge/awareness of hand washing message revealed that respondents from the study area know of handwashing messages.

\section{Research Question Two: Response to Sources of information}

Objective two of the study was to determine the respondents' sources of information of handwashing messages. To further this objective the study formulated this research question: "what are the respondents' sources of information of hand washing?"

The study sought the responses from the nine public secondary schools in South-East Nigeria as indicated from the table below.

Table 6

\section{Mean Distribution of Questionnaire on Response to Knowledge Source}

\begin{tabular}{|c|c|c|c|c|c|c|c|c|}
\hline $\mathbf{S} / \mathbf{N}$ & $\begin{array}{l}\text { Do you know about handwashing } \\
\text { messages? }\end{array}$ & SA & $\mathbf{A}$ & UD & $\mathbf{D}$ & SD & Total & Mean \\
\hline 1 & It is through radio Programmes & $\begin{array}{l}170 \\
(850)\end{array}$ & $\begin{array}{l}45 \\
(180)\end{array}$ & $\begin{array}{c}52 \\
(156)\end{array}$ & $\begin{array}{c}49 \\
(98)\end{array}$ & $\begin{array}{l}19 \\
(19)\end{array}$ & $\begin{array}{c}335 \\
(1303)\end{array}$ & 3.88 \\
\hline 2. & $\begin{array}{l}\text { It is through television } \\
\text { Programmes }\end{array}$ & $\begin{array}{l}175 \\
(875)\end{array}$ & $\begin{array}{l}52 \\
(208)\end{array}$ & $\begin{array}{l}45 \\
(135)\end{array}$ & $\begin{array}{l}42 \\
(84)\end{array}$ & $\begin{array}{l}21 \\
(21)\end{array}$ & $\begin{array}{c}335 \\
(1323)\end{array}$ & 3.94 \\
\hline
\end{tabular}


3. It is through fliers, posters and 165 handbills

4. I don't know of any source of handwashing messages
22

(110)
47

(188)

38

(152)

\begin{abstract}
51
\end{abstract}
(153)

45

(90)

$149 \quad 74$

(447)

(148)
27
(27)
52

$(1283)$

335

(909)
3.83

Figures in Parenthesis are Alternative Response Scale Values

The results from research question two revealed that the highest mean score recorded 3.94 followed by 3.88 and 3.83 indicating that the respondents' information sources for handwashing messages were through television and radio programmes as well as through flyers, posters and handbills. The result further revealed the mean score of 2.71 indicative of the respondents' reaction of not knowing any source of handwashing messages showing negative mean score that should be rejected.

\section{Research Question Three: Response to Practice}

Objective three of the study was to ascertain whether the respondents practice handwashing after exposure to handwashing messages. In pursuance of this objective, the study raised a research question: "Do respondents support handwashing practice after exposure to handwashing messages?" The respondents' opinion was used to answer the research question raised

\section{Table 7: Mean Distribution of Questionnaire on Response to Practice}

\begin{tabular}{lllllllll}
\hline S/N & $\begin{array}{l}\text { How do you practice handwashing } \\
\text { messages? }\end{array}$ & SA & A & UD & D & SD & Total & Mean \\
\hline 1 & I only wash my hands with water. & 48 & 39 & 155 & 47 & 46 & 335 & 2.9 \\
& & $(240)$ & $(156)$ & $(465)$ & $(94)$ & $(46)$ & $(1001)$ & \\
& & & 40 & 139 & 46 & 55 & 335 & 2.9 \\
2. $\quad \begin{array}{l}\text { I wash my hands with soap and } \\
\quad \text { water when my hands are dirty. }\end{array}$ & $(25)$ & $(160)$ & $(417)$ & $(92)$ & $(55)$ & $(999)$ & \\
& & 55 & 60 & 76 & 68 & 76 & 335 & 2.8 \\
3. $\quad$ I wash my hands often & $(240)$ & $(240)$ & $(228)$ & $(136)$ & $(76)$ & $(955)$ & \\
& & 45 & 49 & 120 & 62 & 59 & 335 & 2.9 \\
4. $\quad$ I don't wash my hands at all & $(225)$ & $(196)$ & $(360)$ & $(124)$ & $(59)$ & $(964)$ &
\end{tabular}

Figures in Parenthesis are Alternative Response Scale Values

The table above shows the response to the practice of handwashing messages. All the four items from the questionnaire relating to handwashing practice revealed the mean scores that are below the decision rule, indicative of the respondents' poor performance of handwashing practice.

\section{DISCUSSION OF FINDINGS}

The study was aimed at evaluating the knowledge and practice of handwashing messages among the respondents from the study area. The results of the demographic data of the respondents enabled the researchers to determine the eligibility of respondents in the study area. A majority of the respondents were within the age range of 13-14 (84\%). Therefore, the 
respondents are true representative of all the students in Anambra State. Research questions one and two sought to know about students' exposure to handwashing messages. Results showed adequate knowledge of handwashing messages with positive mean scores of 3 and above ( 3 as decision rule). This was evident in the number and frequency of the surveyed students from the study area that affirmed to the research questions one and two on exposure to handwashing messages. The findings from the study show the respondents were aware of handwashing messages. Also, the findings are in agreement with White et al. (2005) on "the impact of a health campaign on hand hygiene and upper respiratory illness among college students living in residence halls" and found that exposure to media campaign and the availability of gel hand sanitizer; increased students' knowledge of health campaign. Despite the acquired knowledge from the handwashing messages, the practice of handwashing has remained insignificant or low.

The responses from research question three showed that respondents do not practice nor advocate the handwashing messages. These findings are in agreement with the research findings of Azuogu et al. (2016) where the study found the extent of handwashing to be low among secondary school students in Ebonyi. Also, the study is in agreement with the findings of Junxiong et al. (2015) that a high knowledge and attitude of the respondents have not translated to good hygiene practices. Similarly, the study also agreed with Ikogho et al. (2013) and found few availability of handwashing facilities where utilization; was hindered by the maintenance of a few available ones.

The findings also supported Merenu et al. (2015) where it was discovered that majority of the respondents had adequate knowledge of the use of hand sanitizer; while few practised correct hand washing exercise. The findings also supported Mwachiro (2012) where it was observed that lack of provision of soap in schools, inadequate water and disappearance of soap and handwashing facilities as obstacles towards handwashing practice. Therefore, the study found that despite the knowledge acquired from handwashing messages, the practice still remains low.

In line with the diffusion of innovation theory which the study was anchored on, it was observed that the rate of diffusion was influenced by individual differences among potential adopters as well as the social system of the respondents. Though the respondents were exposed to handwashing messages through media information by the government and different agencies like UNICEF, the adoption of the practice of proper handwashing still has to do with individual differences. Also, the social system of the respondents has a lot to offer towards the realization; of the practice of handwashing messages. If the respondents were adequately exposed and have a favourable attitude to handwashing messages without a conducive environment, then the practice of the knowledge gained from these messages may not be realistic. Thus, irrespective of the acquired knowledge from handwashing messages, the practice of handwashing has remained insignificant or very low.

\section{CONCLUSION AND RECOMMENDATIONS}

The study examined the knowledge and practice of handwashing messages among secondary school students in Anambra. The study found that respondents were exposed to handwashing messages, but the exposure did not affect the practice of handwashing. This had a significant impact on advocacy which had also suffered negatively. In essence, handwashing messages will have more impact when the respondents' practice and advocate for handwashing after exposure to handwashing messages. The outcome of the study shows that the practice of 
handwashing was poor, and the respondents' advocacy to the messages was negative. From the above findings and conclusion made, the following recommendations aimed at encouraging handwashing practice in the study area include:

(i) The need to emphasize; handwashing with soap and water at critical times to ensure greater compliance. Also the messages should be designed and disseminated in the patterns that will be attractive and interesting to the respondents.

(ii) Adequate provision and maintenance of handwashing facilities by government, NGOs; and school management to schools in the study area in other to create and sustain handwashing practice among the students.

(iii) Hygiene awareness and public health educationprogrammes should be included in the students' syllabus for proper sensitization; and practice.

(iv) Finally, the use of the findings made from this study to promote handwashing practice among the students in the study area should be encouraged.

\section{REFERENCES}

Abdullahi, I. M., Gbaje, S. \& Mohammed, F.M. (2015). Perceived Attributes of Diffusion of Innovation Theory as a Theoretical Framework for understanding the Non-Use of Digital Library Services. Journal of Information \& Knowledge Management ISSN 2224-896. 5 (9)

Alula, S. (2016). Knowledge, Attitude and Practice on handwashing and associated factors among public primary school children in Hossana town, SNNR, Ethiopia. Addis Ababa University College of Health Sciences, School of Allied Health Sciences. Department of Nursing and Midwifery.

Anthony, M.A., Salule, J.M., Tracy, D.M., George, C.J., Tara, K.B, Steven, E.T. \& Kingsley.L, (2014). Knowledge, Awareness and Practice of the importance of handwashing Amongst children attending State-run primary schools in rural Malawi. International Journal of Environmental Health Research. Vol. 24, ISS.1

Arthi, E., Abarna, V., Bagyalakshmi, R., Anitharaj, M., Vijayasree, S. (2016). Assessment of Knowledge, Attitude and Practice of Hand hygiene among Nursing and Medical students in a Tertiary care Hospital in Puducherry India. International Journal of Contemporary Medical Research 3(4): 1203-1206. ISSN (online): 2393-915X.

Asekun-Olarinmoye, E.O., Omobuwa, O., Adebimpe, W.O. \&Aseku-Olarinmoye, I.O. (2014). Hand washing: Knowledge, Attitude and Practice amongst mothers of under-

five children in Osogbo, Osun State Nigeria. Journal of Biology, Agriculture and Healthcare. $4(16)$

Azuogu, V.C., Ilo, C.I., Nwimo, I.O., Azubogu, B.N., Onwunaka, C.(2016). Extent of Hand Washing practice among secondary school students in Ebonyi State, Nigeria.

European centre for Research Training and Development UK (www.eajournals.org). International Journal of Education, Learning and Development. Vol.4 No. 7, pp. 1122 
Volume 1 Number 1 Maiden Issue

De-buck, E., Remoortel, H.V., Veegaete, V.A. \& Young, T. (2017). Promoting handwashing and sanitation behaviour change in low and middle-income countries. Systematic Review Summary Series. International Development Centre, United Kingdom. www.3ieimpact.org

Ekanem, A.M. \& Johnson, O.E. (2015). Handwashing Practices at Critical times among mothers in selected health facilities in Akwalbom State. Department of Community Health, University of Uyo Teaching Hospital, Uyo, Akwalbom State Nigeria. An official publication of Nigerian Medical Association Akwalbom State Chapter.

Eze, C. (2010). Communication Imperatives for Polio Immunisation Campaign in Rural Areas of Northern Nigeria: The case of Shika Village in Zaria. In D.Wilson (ed.) Perspectives on Communication and Culture. ACCE, Uyo: BSM RESOURCES NIG.LTD;

Ikogho, D.E. \&Igbudu, U. (2013). Availability and Utilization; of Handwashing facilities among primary school pupils in Ughelli North L.G.A; of Delta State. Academic Research International. 4 (5)

Ilesanmi, O. \&Alele, F.O. (2016). Knowledge, Attitude and Perception of Ebola virus disease among secondary school students in Ondo State, Nigeria, PLOS Current outbreak. Edition1.doi:10.1371/currents.outbreaks.

Junxiong, P., Shao, W.J., Lumen, C. \&Liyang, H. (2015). Current Knowledge, Attitude and the behaviour of hand and food hygiene in a developed residential community of Singapore: a cross-sectional survey. BMC; Public Health PMCID: PMC 4475322

Nwabueze, C.D (2012). Evaluating the application of social responsibility theory in developing Societies, In Ekeanyanwu, N.T., Ngoa, S.N. and Sobowale, I.A.(Eds). Critique on the application of communication theories Ota: Covenant University Press.

Nwodu, L.C (2017). Research in Communication and other Behavioural Sciences:

Principles, Methods and Issues. Enugu: RhyceKerex Publishers.

Olalekan, A.W. \&Adeola, E. (2014). How prepared are Nigerian schools for Ebola virus disease prevention and control? Annals of Global Health 80 (6) 452-457 http://dx.doi.org/10.1016/j.aogh.2015.

Olukanni, D.O. (2013). Assessment of WASH Programme in Public Secondary Schools in SouthWestern Nigeria. ARPN Journal of Engineering and Applied Sciences. Vol 8, No. 3. ISSN 1819-6608

Rishante, J. (2011). Analysis of Knowledge, Attitudes and Practices KAP; in relation to Diffusion of Innovation in rural Nigeria Communities (Part 1). In D. Wilson (ed.) Communication for Social Change and development, Uyo: BSM Resources

Setyautami, T., Sermsri, \&Chompikul, J. (2012). Proper hand washing practices among Elemementary school students in Selat Sub-district, Indonesia. Journal ofPublic health and Development; Vol.10 No.2. 
Volume 1 Number 1 Maiden Issue

Steiner-Asadu, M., Van-Ess, S.E., Papoe, M., Setorglo, J., Asiedu, D.k. \& Anderson, A.k. (2011). Hand washing practices among school children in Ghana. Current Research Journal of social sciences 3(4): 293-300 ISSN: 2041-3246.

Thanh Xuan, L.T \& Ngoc Hoat, L. (2013). Hand washing among school children in an ethnically diverse population in Northern rural Vietnam. Vol. 6, ISSN.1, http://dx.doi.org/10.3402/gha.v6i0.18869

Umueri, A. \& Galadima, J. (2008). Role of Communication in Promoting Health Care Delivery, In I.E Nwosu, O.E Soola\& L.C Nwodu (eds.) Communication for Health and Sustainable Development in Nigeria. Enugu: RhyceKerex Publishers.

UNICEF (1998). A manual on school sanitation and hygene. Water environment and Sanitation, Technical Guidelines series No. 5. New York, NY available

Vivas, A., Gelaye, B., Aboset, N., Kumie, A., Berhane,Y., William, M. (2010). Knowledge, Attitudes and Practices of Hygiene among school children in Angolela, Ethiopia Journal of Preventive medicine and Hygiene, 51 (2) 73-79.

Wilson, D. \& Aniebo, S. (2010). Enhancing Public Compliance with Drug Therapy in Nigerian information-poor society. In D Wilson (ed.) Perspective on Communication and culture. ACCE Nigeria Chapter. Uyo: BSM Resources Nig.Ltd.

White, C., Kolble, R., Carlson, R., Lipson, N. (2005). The impact of a health campaign on hand hygiene and upper respiratory illness among college students living in residence halls. J.AM Coll health, July-August 54 (1): 64. 